\title{
Quatrocentos anos num filme: Pindorama (Arnaldo Jabor, 1971) e a relação dos cinemanovistas com a história
}

\author{
Four hundred years in one movie: Arnaldo Jabor's \\ Pindorama (1971) and the relations between Cinema Novo and history \\ Carlos Eduardo Pinto de Pinto* \\ dudachacon@yahoo.com.br
}

Resumo

Após 1968, no âmbito das produções vinculadas ao Cinema Novo, se encontra uma série de filmes históricos construídos por meio de narrativas de vanguarda e visões críticas do passado. Tais produções, muitas vezes encaradas como alegorias que usavam o passado como metáfora para tratar do presente, no auge da repressão da ditadura civil-militar, também podem ser entendidas como agenciadoras de sentidos históricos. Afinal, em sua realização, importava o diálogo com pesquisas historiográficas e, sobretudo, as reflexões a respeito dos mecanismos de funcionamento da história, sendo os cinemanovistas encarados como intelectuais avalizados para esta tarefa. A partir de Pindorama (Arnaldo Jabor, 1971), procuro pensar o papel do Cinema Novo na construção de uma História Pública no Brasil, por meio do circuito de criação e circulação do filme, bem como da cultura histórica de Jabor e outros cinemanovistas.

Palavras-chave: Cinema Novo; filme histórico; cultura histórica.
Abstract

After 1968, regarding productions linked to Cinema Novo, a series of historical films constructed through avant-garde narratives and critical views of the past is made. These productions, often seen as allegories that used the past as a metaphor for dealing with the present at the height of the repression during the civil-military dictatorship, can also be understood as agents of historical senses. After all, they comprehended dialogue with historiographical research and, above all, ideas on the operating mechanisms history, the cinemanovistas being regarded as endorsed intellectuals for this task. Considering Pindorama (Arnaldo Jabor, 1971), I try to think about the Cinema Novo's role in the construction of a Public History in Brazil, regarding the creation and circulation of a film as well as the historical culture of Jabor and other cinemanovistas.

Keywords: Cinema Novo; historical film; historical culture.

* Doutor em História pela UFF. Professor do Departamento de História da PUC-Rio. 
De modo bastante geral, a História Pública pode ser entendida como o campo que se interessa pela delimitação das fronteiras entre a produção historiográfica e outras áreas capazes de difundir e/ou construir sentidos históricos. As experiências de outros solos servem de balizas para as reflexões no Brasil, ainda incipientes: o caráter combativo na Inglaterra, marcado pela vontade política de incorporar, à história "oficial", a visão (a voz e os gestos) de grupos excluídos; os traços mais pragmáticos nos Estados Unidos, em que é forte o interesse pela inserção do historiador na sociedade, procurando pensar eticamente suas atividades fora da academia, sobretudo no que concerne à divulgação da história em mídias diversas (ALMEIDA; ROVAI, 2011).

Especificamente no recorte que me interessa - as relações entre a história e o cinema - percebo um esforço de flexibilização dos papéis exercidos pelos historiadores e pelos profissionais (ou amadores) do audiovisual, o que não assume caráter engajado ou normativo, mas apresenta algumas tensões. Sobretudo, quando se dá o esforço por responder a questões básicas para o campo, tais como: que pontos de contato existem entre um(a) cineasta e um(a) historiador(a)? Que papéis estes profissionais podem cumprir na produção de filmes que reflitam sobre o passado? Historiadores seriam capazes de fazer "bom cinema"? Cineastas estariam aptos a fazer "boa história"? Seria o cinema apenas um mero divulgador da historiografia ou um meio legítimo de criação de sentidos sobre o passado? Os filmes históricos são um bom material didático, sendo possível construir conhecimento a partir deles?

As reflexões que desenvolvo aqui, em torno dos "filmes históricos" cinemanovistas, buscam respostas a algumas dessas perguntas e, com isso, se aventuram no terreno pouco explorado da História Pública no Brasil.

\section{O Cinema Novo e a história}

A partir do fim dos anos 1960 - sobretudo após 1968 - e ao longo da década de 1970, o cinema brasileiro apresentou um boom de filmes históricos, sobretudo os realizados por cineastas vinculados ao Cinema Novo (tanto os da primeira geração, que atuava desde o início dos anos 1960, quanto os mais jovens, que começavam a orbitar em torno do movimento no fim da década). Para a compreensão do impacto destes filmes, considero fundamental alertar para o fato de que não eram obras convencionais realizadas de acordo com a sintaxe cinematográfica hollywoodiana, afeita aos épicos, às reconstituições e aos "filmes de época". Muito pelo contrário, eram filmes históricos modernos, na acepção de Ismail Xavier (2001) ou inovadores, caso se prefira a denominação usada por Robert Rosenstone (2010).

Tais obras seguiam a proposta de refletir criticamente sobre a história e de buscar novas formas de representála por meio da linguagem cinematográfica, num esforço de politização que se aproximava do radicalismo da experimentação vanguardista. Embora não considere que a linguagem clássica hollywoodiana seja despolitizada - nem mesmo que todo filme que siga tal proposta careça, necessariamente, de criatividade - devo ressaltar que, de modo geral, era assim que a questão era tratada entre os anos 1960 e 1970. Robert Rosenstone vem contribuindo para a construção de uma perspectiva diferenciada em relação a este tipo de produção - uma vez que o autor valoriza a linguagem como um dos elementos criadores de sentido, abre a possibilidade de pensar o filme histórico (sobretudo o inovador) como um potencial reinventor da lógica historiográfica e menos como simples difusor da lógica escrita acadêmica.

Visitei esta produção em minha dissertação de mestrado, O futuro do pretérito: a representação da história em filmes cinemanovistas (1968-1980) (PINTO, 2005), desdobrada em alguns artigos. Neles, analisei as relações entre a linguagem cinematográfica e a criação de novos sentidos para a história (PINTO, 2013a); o embate entre os cinemanovistas e a política cultual dos governos militares (PINTO, 2013b) e a disputa pelos sentidos históricos através do circuito de criação e exibição dos filmes (PINTO, 2013c). Em nenhum destes trabalhos me dediquei diretamente a pensar a História Pública, mas consigo perceber, retrospectivamente, a aproximação entre este campo e as temáticas abordadas ali. O contato com as produções de Rodrigo de Almeida Ferreira (2013) foi fundamental para essa constatação, ao perceber que o autor lidava com um material muito próximo ao abordado por mim e lançando mão do referencial da História Pública.

O que faço aqui, portanto, é resgatar um dos aspectos analisados na dissertação - a cultura histórica dos cinemanovistas -, procurando aproximá-la dos questionamentos pertinentes à História Pública. De partida, considero relevante deixar claro que o desejo de repensar o passado pode ser encarado como traço de identidade dos cineastas envolvidos com o Cinema Novo. Trata-se de "uma geração de intelectuais e artistas brasileiros marcados por uma 
Artigos

aguda consciência histórica, sempre atenta à ligação do cultural com o político” (XAVIER, 2001, p. 127). Logo, tal atração pela história era mais que dado contingencial presente na fatura de filmes históricos, embora seja claro que a criação dos mesmos favoreça sua explicitação.

O filme analisado, Pindorama (1971), é a primeira ficção de Arnaldo Jabor, que havia estreado - obtendo grande sucesso de crítica - com o documentário A opinião pública (1967). Por meio da análise de seus elementos diegéticos e narrativos, buscarei compreender os caminhos seguidos pelo diretor e pela equipe na sua criação. Embora enfoque apenas os momentos iniciais da colonização portuguesa no Brasil, a película foi divulgada como uma abordagem de 400 anos de história, através de um contraponto indisfarçado entre os séculos XVI e XX. A recepção da crítica a esta proposta e as elucubrações de Jabor, expostas em diversas entrevistas, são os outros materiais que permitem me aproximar da cultura histórica apreendida e/ou criada pelos cinemanovistas. Darei atenção especial a uma conversa entre Jabor, Walter Lima Jr. e Alex Viany, em torno de dez anos após a realização da obra, em que discutem o papel dos filmes históricos no cinema brasileiro no pós-1968.

\section{Pindorama: o teatro da irracionalidade}

Faltando pouco para o lançamento do filme, selecionado para representar o Brasil no Festival de Cannes, Arnaldo Jabor se referia a ele da seguinte maneira:

Pindorama está me satisfazendo muito, porque acho ter conseguido o que pretendia: um quadro fabuloso e semialegórico de toda a realidade de nossa consciência de povo, de nossa consciência de nação. É uma espécie de grande esboço crítico de nossa psicologia social, de uma psicologia que se vem formando há quatrocentos anos (JABOR, 1971, p. 14).

Esta afirmação, lançada no "espaço de comunicação" (ODIN, 2011) da película - o conjunto de paratextos utilizados em sua divulgação, tais como cartazes, artigos de jornais e revistas, entrevistas, resenhas críticas etc. - se esforça por realizar um direcionamento da construção de sentido. Seja o que for que o espectador venha a assistir, ele já sabe que se trata de uma tentativa por representar 400 anos de história do Brasil.

Uma sinopse de Pindorama, contudo, não corrobora tal esforço. Afinal, Pindorama é uma cidade fictícia localizada no século XVI, onde se desenrolam constantes disputas pelo poder. De um lado da trincheira, o fundador da cidade, D. Sebastião, lutando em nome do rei, com a Igreja Católica. De outro, Gregório, um bardo que defende a autonomia popular, com D. Diogo, um homem muito rico, traidor do rei. Entre os dois, o governador da cidade, político sem escrúpulos que muda de lado conforme o melhor proveito que possa tirar. Também contra D. Sebastião, mas sem uma motivação política evidente, está sua esposa, figura quase mítica, uma espécie de Medeia quinhentista. Para todos os efeitos, se trata de uma história localizada no tempo, representando um passado distante e não a totalidade dos 400 anos anunciada pela fala de Jabor.

Contudo, as linhas gerais que me esforcei em construir no parágrafo anterior, ao modo de uma sinopse, não são suficientes para definir Pindorama. Não é possível compreender o filme relatando apenas o que acontece nele, sendo necessário saber também como acontece. No texto que serve de abertura ao filme, a última frase ajuda a confirmar tal percepção: "Os fatos aqui narrados são imaginários, se bem que verídicos".

Neste sentido - do encontro do imaginado com o verídico - considero fundamental perceber que os personagens apontados na sinopse não são históricos (não se trata da representação de pessoas "reais" que viveram no passado) nem apresentam complexidade psicológica. São, de forma mais precisa, arquétipos ou personas - como as máscaras de teatro grego, que representavam uma generalização de sentimentos e atitudes e não uma personalidade individualizada. D. Sebastião não é histórico, mas através dele são representados “todos” os desbravadores históricos reduzidos a traços mais gerais, o mesmo acontecendo com os demais personagens.

As ações, assim como o "desenho" dos personagens, também são esquemáticas, correspondendo a reações a dois elementos básicos: o poder de Além-mar (o rei) e o povo. É possível estar contra o poder do rei e ser contra o povo simultaneamente, como o governador e D. Diogo. É possível estar a favor do rei e desejar salvar o povo como fazem D. Sebastião e a Igreja. É possível ser contra o rei e estar do lado do povo, como o artista. É possível não se definir em relação a esses dois elementos, como a mulher de D. Sebastião, cujo egocentrismo se manifesta no alheamento às questões políticas.

Outro ponto fundamental é que a narrativa é marcada pela contemporaneidade. A história dessa cidade 
fictícia está sendo contada em 1970 e, quanto a isso, não restam dúvidas. Desde o uso de fotografias na abertura, passando pela trilha, pelos figurinos e cenários híbridos, equilibrando fortes referências à contemporaneidade com a tentativa de manter alguns traços de contato com a estética do período retratado. A música da abertura, com uso de sax e vocais arrojados, em nada lembra a musicalidade europeia do século XVI, porém, em outros pontos da narrativa, essa proximidade é buscada pelo uso de batuques e cânticos indígenas no som diegético. Em relação aos figurinos, em lugar de tentar uma aproximação do visual quinhentista, Pindorama opta por referências superficiais a ele, pois as indumentárias apenas lembram o século XVI. Os cenários seguem o mesmo estilo, podendo funcionar como referência ao passado (nunca uma reconstituição fiel) e como cenário teatral.

A recorrência à linguagem teatral - mais especificamente da matriz brechtiana - é reforçada pelo uso do plano aberto no enquadramento e pela frontalidade das atuações. As personagens, a maior parte do tempo filmadas de corpo inteiro, quebram a quarta parede falando mais com o público (com a câmera) do que uns com os outros. E, mesmo quando dialogam entre si, permanecem de frente para a objetiva. Esta encenação não naturalista - empenhada menos em distrair o espectador que em fazer com que ele se lembre, a todo tempo, de que o filme é um simulacro - é uma das chaves que permitem compreender por que Jabor se esforça por tratar de 400 anos de história. Afinal, tais recursos ancoram a encenação do passado no presente, "contaminando" a linguagem cinematográfica com o imediatismo da linguagem teatral. Um circuito se fecha, e o século XVI se mostra explicitamente contido pelo século XX.

No início, são apresentadas sequências em que os personagens vão sendo apresentados, sempre no registro da teatralidade brechtiana, do discurso assumidamente encenado. Dom Sebastião tem seus atributos reforçados por uma encenação feita por índios dirigidos por um padre jesuíta. Em plano aberto, com a câmera estática, um grupo de índios representa a si mesmo. Outro conjunto de índios entra no quadro para representar D. Sebastião e seu exército: têm os rostos pintados de branco, usam asas cenográficas e carregam trombetas. Um dos índios esquece sua fala, e o padre entra no quadro, se posta a seu lado e fala por ele: "Como é bom viver nos matos, nos rios, nas cachoeiras! Comer a carne dos brancos, entre sóis e tempestades. Felizes a vida inteira!”. O índio que representa D. Sebastião se aproxima do que representa o chefe da tribo (o mesmo que esquecera a fala) e lhe mata na cena.

Por meio desse exemplo, fica patente como a estrutura da obra de Arnaldo Jabor repete o didatismo das encenações dos primeiros catequistas do Brasil. Há, na estrutura da sequência em que o padre "entra em cena" para falar pelo índio colonizado, o esforço de criação de um sentido de leitura que leve à crítica, por parte do espectador, da atuação alienante da Igreja no período colonial. Por outro lado, fica evidente que esse mesmo didatismo "contamina" o filme, repetindo o mesmo erro (com intenções obviamente distintas) que procura criticar.

Mais adiante, D. Diogo, o "homem rico", cercado de figurantes, diz: "Ninguém segura mais a gente! Nem o rei! Louvado seja o reil". Em seguida: "Meu povo, me desenvolvendo como...". Aqui o ator se atrapalha com a articulação de sua pronúncia e balbucia alguma coisa ininteligível, assumindo o erro. A figuração ri dele. É interessante que esses elementos estejam contidos na montagem final, já que funcionam como uma rejeição ao ilusionismo da linguagem clássica e reforçam o estatuto teatral da encenação, em que um erro de elocução não pode ser contornado com um corte na montagem.

Esta leitura é reforçada pelo personagem Gregório, apresentado como um “cantador” que se dedica a, por meio do "teatro educativo", apontar os erros dos poderosos e falar em nome do povo. Uma de suas encenações repete explicitamente ações que os poderosos acabaram de realizar, o que causa grande irritação quando os mesmos percebem a lógica deste jogo.

Aproximadamente metade do filme é dedicada à apresentação dos personagens e à definição dos conflitos. Como indiquei acima, é possível marcar as posições ocupadas por cada um em termos genéricos. A mulher de D. Sebastião é um caso especial, pois representa muitos elementos simultaneamente. Nenhum deles pode ser descrito em termos muito concretos - as forças sobrenaturais, a alienação, o irracional - mas sua presença é muito importante, como demonstro a partir de agora. Ela ajuda a demarcar uma oposição importante no filme: masculino, razão, lealdade, cristianismo vs. feminino, irracionalismo, traição, paganismo.

A segunda parte do filme se dedica a encenar uma contaminação gradual dos arquétipos pelo irracionalismo. Daí a importância do papel da mulher, que serve de contraponto à razão colonizadora que domina as outras personagens, extremamente lúcidas. Para reforçar tal função, devo enfatizar que somente a mulher apresenta um comportamento animalesco nas sequências iniciais. Aos poucos, porém, os outros personagens também passam a gritar, a se contorcer, a urrar e, em alguns casos, a uivar. Ao fim do filme estão sujos de lama, desesperados, inconsequentes, 
Artigos

extremamente emotivos. Embora não haja um esforço aparente por parte da mulher para "contaminar" os outros, penso que essa transformação funcione como uma espécie de vingança das forças irracionais que ela representa contra o racionalismo da colonização ou da "conscientização", esta representada pelo artista.

A última sequência do filme representa o encontro de D. Sebastião com o corpo de Gregório, o cantador, que é carregado por dois soldados. Dom Sebastião não fala nada, apenas recolhe o corpo do meio da lama em que os dois homens o jogaram e o leva nas costas. Vagueia pelo espaço amplo (plano aberto, quadro estático), se aproxima da câmara e começa a gritar ininterruptamente, cada vez mais alto. Enfim, encara a objetiva, ainda gritando, e sai do quadro pelo lado esquerdo. Há um corte brusco e a tela fica azul, indicando o fim.

Dom Sebastião é o único que chega ao final da narrativa - provavelmente representando a longevidade do poder dos militares - embora contaminado pelo irracionalismo e carregando o peso incômodo do corpo de um artista morto.

\section{O Cinema Novo e a cultura histórica}

$\mathrm{Na}$ mesma entrevista citada acima, em que Jabor indicava sua intenção de representar 400 anos de história, ele afirmava, enfaticamente: "Precisamos não considerar que vivemos um período histórico único no mundo. Estamos vivendo apenas um período histórico". (JABOR, 1971, p. 15. Ênfase minha).

Em outro artigo sobre Pindorama (PINTO, 2008), interpretei esta afirmação contrapondo-a ao resultado da análise do filme. Considerei que havia um descompasso entre o que Jabor afirmava e o que fazia, já que o filme parece, o tempo todo, falar do presente - o que denota uma importância maior do que aquela que ele parece querer lhe dedicar na entrevista. No fim das contas, minha leitura do filme terminava por reafirmar que se vivia, sim, "um período único no mundo". Terminei por interpretá-lo como uma alegoria, que usava a história - no caso, o início do século XVI - para tratar do presente. Hoje, após travar contato com outras reflexões, opto por rever meu posicionamento.

Considero mais interessante perceber que Jabor - a despeito de o filme poder ser considerado uma alegoria - também cumpre o prometido, flexibilizando os recortes cronológicos e sendo capaz de tratar de 400 anos de história por meio de uma diegese ancorada no século XVI e de uma narrativa que reforça a contemporaneidade. É justamente nesta abertura narrativa - que cria um arco temporal colando o passado ao presente - que se dá a criação de sentidos.
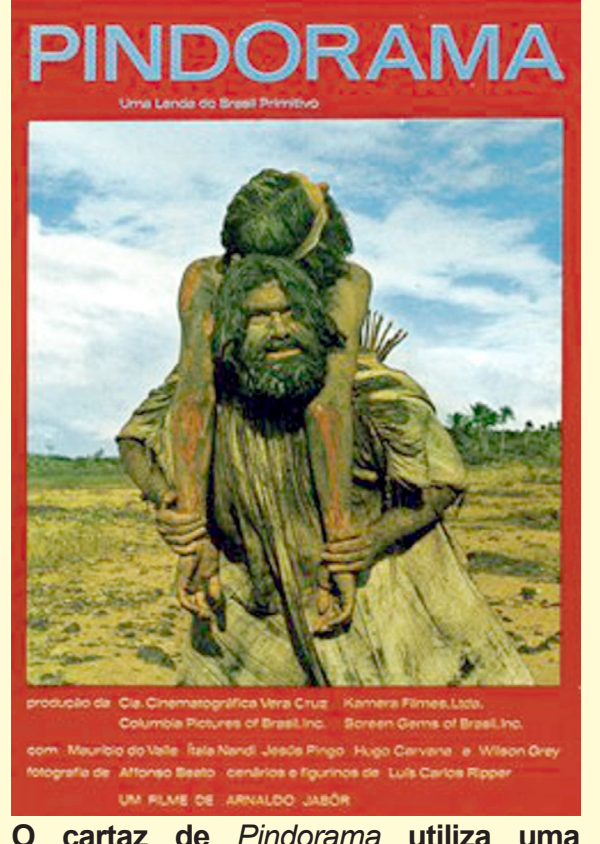
fotografia da sequência final. Também aqui, se reforça a frontalidade dos atores em prol de uma teatralização das ações. Fonte: http://www.bahiaflaneur.net/ blog2/2010/05/miguel-rio-branco-la-ferveurchromatique.html
De fato, já percebera esta abertura na dissertação e no artigo, mas não havia compreendido que ela poderia ser uma chave de interpretação mais potente do que a ideia de alegoria - o que me fez buscar a "contradição" como uma saída explicativa fácil. Agora, pretendo explorar mais a ideia de que Jabor se considerava capaz de tratar de 400 anos de história, procurando entender como isto pode contribuir para a construção de uma História Pública no Brasil durante os anos 1970. Estou interessado, aqui, em abordar outros discursos do diretor que possam dialogar com o discurso fílmico - não porque considere que Jabor deva "explicar" seu filme, mas porque estou no encalço da coerência de seus propósitos na produção de sentidos para a história.

Em O Processo do Cinema Novo (1999) estão reunidas entrevistas, realizadas por Alex Viany entre 1964 e 1986, com diretores cinemanovistas. A proposta do cineasta e crítico era provocar e registrar a reflexão dos criadores sobre suas obras, além de permitir a observação - por meio de entrevistas coletivas - do contraste entre as opiniões de quem formava o movimento. Em uma entrevista de 1978, Arnaldo Jabor e Walter Lima Jr. estabelecem um embate a respeito da trajetória traçada pelo Cinema Novo a partir de 1968. Ainda que os trechos sejam longos, optei pela transcrição, por considerar que esta escolha mantém a dinâmica das falas e permite uma reflexão mais aprofundada. Jabor inicia: 
Bem, Alex, você pergunta sobre os últimos dez anos. É uma boa pergunta, porque 1968 é um marco na história da cultura brasileira. É uma data importante - se é que existe cultura brasileira, se é que existem marcos históricos, porque essas são duas categorias discutíveis. É o momento em que foi dada uma grande marretada nas cabeças pensantes do Brasil. Uma repressão muito grande, cultural, política, etc. Difícil fazer uma síntese do que aconteceu, porque essas sínteses geralmente pecam pala tentativa de globalização das coisas. Juntar tudo, juntar as pontas de uma meada que às vezes não é contínua - esse é um vício antigo que a gente tem. Eu mesmo, por exemplo, tenho a mania de querer dar uma continuidade histórica às coisas, dar um sentido. Isso é um velho vício idealista. Acho que não dá para fazer um desenho coerente do que aconteceu nos últimos dez anos do cinema brasileiro, mas dá para destacar alguns pontos importantes. Uma das coisas principais: os filmes estavam aparecendo num período (não sei se pré ou pós-68) de uma certa crise ideológica. Uma crise de criação. De um lado, o Cinema Novo, que tinha surgido dez anos antes... (VIANY, 1999, p. 227).

Nesse momento, é interrompido por Walter Lima Jr., que não concorda com a ideia de uma crise em 1968. Discutem por algum tempo. Jabor tentando dar continuidade ao seu raciocínio e Walter insistindo em interrompê-lo. Jabor finalmente prossegue:

(...) Então: de 1968 para cá. Eu sinto esses pontos assim - mas não estou querendo ligá-los, conectá-los numa coisa coerente. Sinto, por exemplo, uma vontade muito grande, no chamado Cinema Novo, vontade que chegou a um beco sem saída em 1968: fazer um cinema conceitual, um cinema que conceituasse a realidade brasileira. (...) O Cinema Novo era um cinema que queria se fazer, um cinema materialista no sentido histórico da palavra, entende? Esse projeto em 1968 chegou ao ponto mais rico de sua evolução e foi interrompido por uma repressão política muito forte - que fez com que os filmes, vamos dizer assim, tenham enlouquecido o que estavam dizendo, tenham sido levados a criar uma espécie de terceira linguagem para dizer coisas que queriam dizer e que já não podiam ser ditas então. Houve uma espécie de 'cancerização' do cinema brasileiro em 1968. Ele entrou num beco sem saída, porque partia para uma jogada conceitual, uma atitude de explicitação dos traços maiores da realidade, e de repente isso ficou muito difícil, ficou impossível. Então os filmes entraram no que geralmente se chama de delírio, de fase alegórica etc. Uma característica não sei se boa ou má. Seu Brasil ano 2000... [refere-se a um filme de Walter Lima Jr.]. O meu Pindorama... O Azyllo muito louco, do Nelson... Os herdeiros, do Cacá... Filmes bem dessa época (VIANY, 1999, p. 229).

Para além do debate em torno da importância de 1968 para a cultura brasileira, que considero bastante atraente, cabe aqui chamar atenção para o fato de que as falas são marcadas pela busca de um sentido histórico. Jabor a rejeita, chamando de "velho vício idealista", mas, ainda assim, continua a praticá-la, traçando um panorama retrospectivo de sua geração, buscando explicações coerentes para seus atos. É certo que, nesta tarefa, segue a proposta da entrevista de Alex Viany, mas - ele mesmo o percebe - assume uma postura geracional (e aqui não me refiro apenas ao grupo de cineastas, mas a todos que tinham em torno de 20 anos no início dos anos 1960).

Para esta geração, a história só tinha um caminho a seguir - a mudança - cabendo a eles efetivar o processo. No caso dos jovens cineastas, a sua arte era considerada a principal arma: faziam filmes como quem faz história. E isso não significa que tivessem um apreço especial pelos filmes históricos, ao contrário: esse tipo de produção aparece tardiamente em suas filmografias ${ }^{1}$. Mas a história sempre esteve presente, ainda que como uma sombra, perpassando os propósitos com que essa geração filmava. O desejo de conhecer e representar o Brasil incluía necessariamente o reconhecimento do seu passado, como pode exemplificar esse trecho de uma entrevista com Leon Hirzsman:

[O Cinema Novo] esteve dentro do processo da cultura brasileira que tentou mapear o país. Acho que a literatura de 1930, na literatura regional - Graciliano, Jorge Amado, José Lins do Rego, Érico Veríssimo - cada um tentou a seu modo expressar a recuperação da realidade social, popular, de certas regiões. E estudar a História também. O Cinema Novo veio dar sequência a isso, acredito. Assim como o teatro de Arena, de São Paulo, tentou botar o homem brasileiro como sujeito da sua história. O Cinema Novo deu sequência a esse tipo de aproximação, a esse processo, mas já dentro de uma perspectiva de linguagem, tentando ser também uma linguagem nova. (...) Além de ser um pensamento sobre a realidade social, política e econômica do país, além de tentar mapear o nordeste, a favela, o trabalho industrial, o marginal, os explorados, os oprimidos, e os sem voz, além de dar espaço para eles nos filmes, além disso, o Cinema Novo foi também resultado da necessidade de abrir espaço para expressão pessoal de cada cineasta (VIANY, 1999, p. 311. A entrevista é de 1983).

Penso ser importante informar que tais tarefas, de grande complexidade, eram acompanhadas de um reconhecimento social. Como informei inicialmente, tal geração é encarada, mais do que como um grupo

1 Devo lembrar a exceção de Cacá Diegues que filma Ganga Zumba ainda em 1964. 
Artigos

de artistas, como um conjunto de intelectuais que fazem arte. Seriam, portanto, profissionais avalizados para construir um pensamento sobre a história (e a sociologia, a antropologia, a política etc.) do país.

A história não era vista por eles como um "espetáculo" perdido no passado e assistido por um presente estável, bem definido: era uma ação presente, ainda sendo realizada. E "fazer a história” era um dos objetivos que os cinemanovistas almejavam alcançar ao fazer cinema. Contudo, o golpe civil-militar de 1964 veio destruir essa crença, representando o fim da ideia de uma história dócil e submissa. Os jovens cineastas ainda tentavam entender o golpe e perceber suas consequências quando, em 1968, o AI-5 chegou para não deixar mais espaços para dúvidas. Com a suspensão dos direitos civis e políticos, qualquer passo em falso poderia resultar em prisão, exílio ou "desaparecimento". A insubordinação da história tornara-se palpável a partir do ponto em que ela se recusou a seguir os rumos determinados pelos jovens, num processo semelhante ao que Daniel Aarão Reis detalha em $A$ revolução faltou ao encontro (1991).

É neste momento que passam a ser produzidos os filmes históricos modernos ou inovadores, como Pindorama. Embora não descarte a relação dos cineastas com a ditadura - afinal, havia uma política cultural com a qual os cineastas precisariam dialogar, caso desejassem continuar filmando - considero uma solução limitada assistir a esses filmes como metáforas do presente que utilizavam uma "capa" de passado para driblar a censura. Tampouco acho válido ficar apenas no plano da comparação entre a produção historiográfica e a "recriação" cinematográfica - o que, no caso de Pindorama, resultaria praticamente nula, tamanha a liberdade criativa do processo de fatura do filme. Penso ser mais interessante encarar este e outros filmes do período também como o resultado das relações de força estabelecidas entre os anseios de seus criadores e a história, percebida como uma entidade fantasmagórica, morta-viva traidora.

Em resumo, tais filmes podem ser uma porta de acesso para se compreender o contexto em que foram realizados, sim, mas esta operação não deve seguir apenas o rastro das alegorias do presente (dos anos 1960 e 1970). Eles são, igualmente, reflexão sobre os mecanismos de funcionamento da história, uma busca pela compreensão de como os processos históricos poderiam ser desenvolvidos.

\section{Crítica: o que se diz e o que se entende}

A despeito do aval da sociedade para tratar do tema a que me referi acima, não se deve considerar que os filmes históricos cinemanovistas fossem unanimemente aceitos pela crítica profissional. Pelo contrário, havia um deslizamento constante entre a ovação e a ojeriza a tais produções - sendo a primeira praticada por aquela parcela da crítica que acatava a experimentação vanguardista como forma legítima de produção de conhecimento e a segunda, pelos críticos mais apegados aos parâmetros associados aos filmes históricos clássicos - linearidade e transparência. Embora sem dados concretos que apontem este paralelismo, considero plausível que o mesmo acontecesse com o público.

Com Pindorama não foi diferente: ao mesmo tempo em que recebeu atenção especial da revista Filme Cultura, já citada anteriormente (vale lembrar que não se tratava de uma crítica, mas de uma entrevista com o diretor), foi rejeitado por O Globo. Para este veículo, "sob o prisma espetacular, [Pindorama] é o antifilme, uma desagradável sucessão de imagens desordenadas, anacrônicas e rebuscadas que raramente estabelece qualquer comunicação com o público” (PINDORAMA, 1972, p. 8).

Outros filmes históricos inovadores recebem tratamento semelhante, como Os deuses e os mortos, de Ruy Guerra, e A guerra dos Pelados, de Silvio Back, ambos de 1970. No caso do primeiro: "Desconfia-se que a intenção era fazer o levantamento de toda uma época, seus sonhos, mitos e sugestões. Saiu um garrancho com pretensão a documento, falado em português pedante dos bacharéis do interior baiano" (PAISAGEM VAZIA, 1972, p. 82). Sobre Guerra dos pelados: "Desconfia-se que os fatos narrados eram suficientemente importantes para a feitura de um filme político e vários motivos podem ter turvado sua desejável clareza" (COMO É MESMO?, 1972, p. 87).

Destaco a expressão "desconfia-se”, utilizada com insistência nas duas últimas críticas, que reforça seu posicionamento em relação aos filmes. Como eles não são didáticos, não possuem clareza, não é possível ter certeza a respeito do que tratam. E, quando não se pode ter certeza... desconfia-se. 


\section{De volta à História Pública}

Para o objeto principal de minha reflexão - pensar as relações entre o cinema e a História Pública o comportamento da crítica especializada permite reflexões valiosas. Afinal, seu embate com os filmes se configura como uma das etapas de construção de sentidos. Do processo de criação à recepção (incluída a crítica), se dá uma série de negociações que visam reconfigurar a percepção do que seja a história. Trata-se de um processo de (re)construção da cultura histórica, considerada a relação que uma sociedade mantém com seu passado, pautada não apenas pela historiografia, mas também pela cultura política (GOMES, 2007). Desse modo, o filme histórico seria um encontro privilegiado do cinema com a história, capaz de mobilizar esforços diversos de recriação de sentidos, estimulando reflexões e combates em torno de determinados temas ou - como acredito ser o caso de Pindorama - em torno do próprio sentido do que seja a história.

Defendo, portanto, que as relações entre o cinema e a História Pública podem ser bem mais complexas do que uma simples "transcrição" ou "tradução" das produções acadêmicas em linguagem cinematográfica. O cinema é um espaço autônomo de criação de sentidos para a história, sobretudo quando tratamos de filmes históricos modernos (XAVIER, 2001) ou inovadores (ROSENSTONE, 2010), como é o caso de Pindorama.

\section{Referências}

AARÃO REIS Filho, Daniel. A revolução faltou ao encontro. São Paulo: Brasiliense, 1991.

ALMEIDA. Juniele Rabêlo; ROVAI, Marta Gouveia de Oliveira (Orgs.). Introdução à

História Pública. São Paulo: Letra e Voz, 2011.

COMO É MESMO? Veja, no 161, 6/10/1971.

FERREIRA, Rodrigo de Almeida. Produção Cinematográfica e História Pública: Chico Rei (1985). In.: BELCHIOR, Luna Halabi; PEREIRA, Luisa Rauter; MATA, Sérgio Ricardo da (Orgs.). Anais do $7^{\circ}$. Seminário Brasileiro de História da Historiografia - Teoria da história e história da historiografia: diálogos Brasil-Alemanha. Ouro Preto: EdUFOP, 2013.

GOMES, Angela de Castro. Cultura política e cultura histórica no Estado Novo. In: ABREU, Martha et al. Cultura política e leituras do passado. Rio de Janeiro: Civilização Brasileira, Faperj, 2007.

JABOR, Arnaldo. O verdadeiro artista tem de aguentar firme. Filme Cultura, Ano III, nº 17, nov/dez 1970.

ODIN, Roger. Les espaces de communication. Introduction à la sémio-pragmatique. Paris: Presses Universitaires de Grenoble, 2011.

PAISAGEM VAZIA. Veja, n. 158, 15/ 09/ 1971.

PINDORAMA. O Globo, 18/03/72.

PINTO, Carlos. E. P. de. O futuro do pretérito: a representação da história em filmes cinemanovistas (1968-1980). Dissertação (Mestrado) - Pontifícia Universidade Católica do Rio de Janeiro, Rio de Janeiro, 2005.

. Luz, câmera, política! Pindorama e a busca pela identidade histórica brasileira. In: Anais eletrônicos [do] XIII Encontro de História Anpub-Rio - Identidades, 2008.

. História, sexo, risos: quem tem medo de Xica da Silva? Fronteiras (Florianópolis), v. 1, p. 33-52, 2013 a.

Relatos Fantasmas: os filmes históricos cinemanovistas e a política cultural da ditadura civil-militar nos anos 1970. REBECA. Revista Brasileira de Estudos de Cinema e Audiovisual, v. Ano 2, p. 62-88, 2013 b.

Sob o signo da ambiguidade: uma análise de Anchieta, José do Brasil. Significação-Revista de Cultura Audiovisual, v. 40, p. 74-95, 2013 c.

ROSENSTONE, Robert. A bistória nos filmes, os filmes na bistória. São Paulo: Paz e Terra, 2010.

XAVIER, Ismail. O cinema brasileiro moderno. São Paulo: Paz e Terra, 2001. 